\title{
The Emotional Approach of Foreign Vowel Acquisition Within the Example of British English Vowels
}

\author{
Michał Wyciński \\ Łomża State University of Applied Science, Łomża, Poland
}

\begin{abstract}
The aim of the article is to present results of research that was performed with 97 Polish students of the second and third year of English Philology. The purpose of the research is to examine how conscious manipulation of facial expressions aids acquisition of foreign vowels by learners, regardless of their native language and the culture they have been brought up in. Taking advantage of achievements derived from such disciplines as psychology of emotions and phonetics depicted as a physical process, an attempt is made to find a tool that improves teaching/learning of foreign vowels, that is to say, an effort is put in search of a useful method to make the phonetic process faster and more accurate. Teachers of English are encouraged to put the method, which is described in detail in the paper, into practice with their own mother languages and to share opinions about the method with colleagues. Similarly, it is believed that it can be applied to courses of other languages than just English. Teachers of those languages are encouraged to try to use it, too.
\end{abstract}

Keywords: foreign vowels acquisition, British English vowels, emotions, facial expressions

\section{Emotions and Facial Expressions}

In a groundbreaking publication Unmasking the Face: A Guide to Recognizing Emotions From Facial Clues, Paul Ekman and Wallace Friesan (1975) describe their own studies of the relationship between emotions and facial expressions, along with the conclusions of their research. They answer questions such as: "How many emotions are there? What are their facial clues? Are emotions universal or do they have a cultural background?" Ekman and Friesan are pioneers in terms of research on the universality of emotions (Earlier studies were arbitrary and subjective (Knapp \& Hall, 2000, p. 416)). The conclusions they have drawn constitute a datum for the given paper, whose objective is to present how useful achievements from the field and psychology of emotions are in the practice of British English vowels pronunciation.

One of the first attempted experiments by Ekman and Friesan was conducted in a closed lab. Students from the USA and Japan took part in it. The students were given a piece of stress-inducing film to watch, while their facial expressions were recorded on a videotape during the session. Japanese students tended to repress their expressions more than U.S. students. However, regardless of intensity, both groups revealed the same

Michał Wyciński, lecturer, master, Institute of Social Science and Humanities, Łomża State University of Applied Science.

Michał Wyciński-is an M.A. graduate of English Philology, specializing in cognitive linguistics. He has been teaching English for 10 years. During that time, he has been working with people of different age groups, employing various methods of teaching. Currently, he is working as an academic teacher, conducting classes in English methodology and British phonetics. He is embarking upon interdisciplinary research in the fields of psychology, sociology, and linguistics. He is studying the relationship between cognition, emotions, and memory in teaching foreign languages, paying particular attention to neurolinguistics and British phonetics. Email: michal.wycinski@gmail.com. 
expressions as indications of emotions triggered by a bit of film. Ekman and Friesan distinguished six of these emotions: happiness, fear, surprise, sadness, anger, and disgust. Each of these emotions has their representation observed in facial clues. The clues are: ${ }^{1}$

Happiness - crow's feet wrinkled, pushed up cheeks, movements from muscles that orbit the eye;

Fear-eyebrows raised and pulled together, raised upper eyelids, tensed lower eyelids, lips slightly stretched horizontally back to ears;

Surprise - eyebrows raised, eyes widened, mouth open;

Sadness - dropping upper eyelids, losing focus in the eyes, slight pulling down of lip corners;

Anger-eyebrows down and together, eyes glare, narrowing of the lips;

Disgust—nose wrinkling, upper lip raised.

The pictures of facial expressions found in the reference only stand for exemplary pictures of emotions. It is palpable that they can be expanded in a number of ways in terms of intensity of the movement and position of facial muscles; on one hand, there might be an overreaction and exaggeration of expressions, on the other hand, they might to be suppressed and barely noticeable. Thus only the clearest (the most "moderate") illustrations of facial expressions are displayed in the course of the research.

Having a "completed" set of emotions, Ekman and Friesan started showing pictures of facial expressions to a greater audience. They expanded the group of informants to include individuals from countries such as Chile, Argentina, and Brazil. It turned out that (apart from a few exceptions-most likely conditioned individually) the ability to recognize emotions ranged from $90 \%$ to $100 \%{ }^{2}$

Obviously, there was still a possibility that facial reactions to cinematographic stimuli and the ability to recognize emotions presented in the pictures might have been conditioned culturally. Ekman and Friesan wrote:

All the people studied had some shared visual contact, usually not directly but through mass media. It was still possible that (...) the people might have learned (facial expressions) through movies, television, and picture magazines, what each other's facial expressions of emotions looked like. (Ekman \& Friesan, 1975, p. 26)

In order to resolve the dispute, the scientists sought to find a culture that seemed to be as "isolated" as possible, meaning that the culture which had a limited or no access to the media, a culture with no previous contact from "the outside world".

Such a culture was found in New Guinea, where a series of the same studies (emotional reactions to stimuli, recognizing emotions) was carried out amidst people whose interactions were mainly limited to interpersonal ones. Conclusions from those studies confirmed what had already been assumed and gave conclusive proof: Emotions are universal regardless of culture and have their corresponding facial expressions. Forehead, eyebrows, eyes, nose, mouth, cheeks, and chin which are combined with other facial muscles make the total of 54 that can form unique and universal expressions as emotional reactions to specific stimuli.

Ekman and Friesan distinguished six basic emotions (Ekman \& Friesan, 1975). In the 80's Ekman set a series of further tests to explore those primary emotions. As a result, he introduced the notion of secondary

\footnotetext{
${ }^{1}$ Photos with examples of facial expressions can be found in Ekman Paul and Friesan Wallace (1975). Unmasking the face: A guide to recognizing emotions from facial clues (pp. 44, 57, 73, 91, 108, 120). Cambridge: Malor Books. They have not been published in the article due to respect for author's right of the pictures.

2 A complete table presenting the results of the survey can be found in Ekman Paul and Friesan Wallace (1975). Unmasking the face: A guide to recognizing emotions from facial clues (p. 25). Cambridge: Malor Books. The table has not been printed in the article due to respect for author's right of the pictures included in the graph.
} 
emotions (derivations), that is to say, emotions triggered by primary ones. Ekman expanded both of them in The Nature of Emotion: Fundamental Questions (Ekman \& Davidson, 1994) and Emotions Revealed: Recognizing Faces and Feelings to Improve Communication and Emotions (Ekman, 2003). Due to a vast number of emotions cited in the literature and their intricate nature, only certain emotions are used for the purpose of the research presented subsequently.

\section{Physicality of Vowels}

There are plenty of textbooks on teaching English pronunciation, e.g., Komorowska (Komorowska, 2005, pp. 136-145), Harmer (Harmer, 2001, pp. 183-197), Scrivener (Scrivener, 2005, pp. 284-297) or Kelly (Kelly, 2000). Much as the authors strive to put the methodology of phonetics into practice, apart from a few exercises on rhythm or intonation, their approach boils down mainly to a mental process. Underhill believes that constitutes a crucial problem (Underhill, 2012). As he makes his claim, learners need to:

Make pronunciation physical, visible, audible! Move it out of their head and make it a physical process. While grammar and vocabulary may somehow take place "in the head", pronunciation is the physical aspect of language; it manifests through the body. ${ }^{3}$

It is somewhat obvious that state schools may not offer a sufficient amount of time for this particular component in regular foreign language classes (Komorowska, 2005, p. 136; Harmer, 2001, p. 183). Nevertheless, at universities, particularly in philology faculties, given the resources of space and time, it is vital to make students aware that if they aim at achieving correct British English pronunciation; they have to activate the whole body, which means to make a connection between the muscles and the brain.

To account for the statement, especially in terms of understanding British English vowels, Underhill proposes an exercise. He tells the course participants to first pronounce /i:/, then /u:/, paying attention to the movement of the articulators. When producing /i:/, the lips are stretched; the tip of the tongue is closer to the teeth; during /u:/ the tip of the tongue moves backwards; towards the throat and the lips are formed in a solid round.

The author of the article recommends a similar exercise, with the sounds /i:/ and /a:/. Again, the principle governing the task is not only to observe the muscular changes, but to feel them. Putting the tip of the index finger to the tip of the tongue is vital in this case. With /i:/ the lips are stretched and the tip of the tongue goes in the direction of the teeth. With /a:/ the jaw drops; mouth opens; the tongue moves towards the oesophagus. The author chooses these two sounds on purpose. Firstly, they do not have their Polish equivalents. Secondly, there is a tremendous difference in terms of movement within the area of the oral cavity between the production of British English and Polish vowels. Taking into account the cardinal vowel diagram (see Figure 1), pronunciation of a Polish set, that is to say of /i/ and /a/ (indicated by a dotted arrow in the graph) causes the articulators to cover a smaller distance and to put less effort by the speaker than pronunciation of English /i:/ and /a:/ (indicated by a straight line in the graph). ${ }^{4}$

\footnotetext{
${ }^{3}$ Underhill, A. (2012). Make pronunciation physical, visible, audible! Macmillan Online Conference, Macmillan.

${ }^{4}$ More exemplary exercises by Underhill and the author of the article on physicality of speech can be found in:

Underhill, A. (2007). Successful pronunciation learning. Teacher Training Workshop DVD, Macmillan. Wyciński, M. (2013). Psychofizjologia i emocje w nauczaniu fonetyki języka angielskiego. Łomża: PWSIiP.
} 


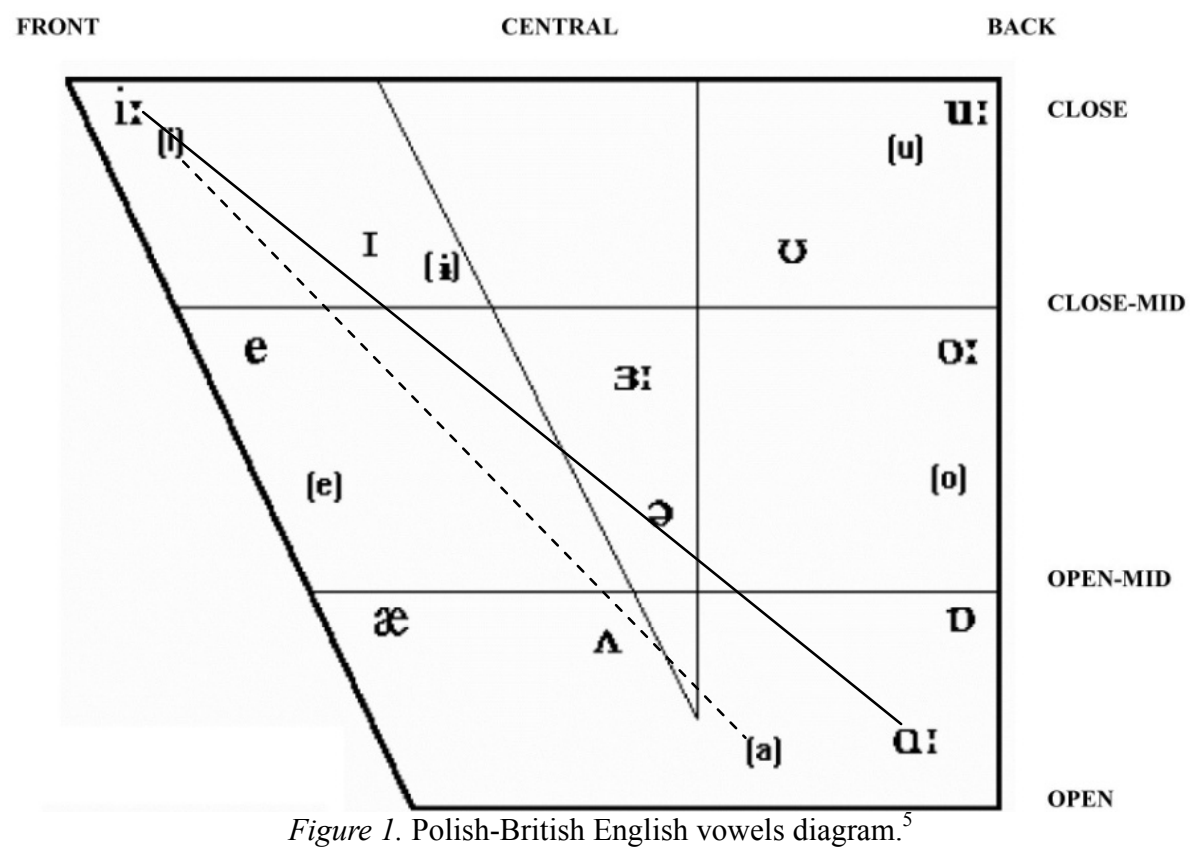

The divergence between pronunciation of Polish and English vowels is a result of deeply rooted habits of the users of both languages. The main differences between the vowels that Sobkowiak enumerates are: number of vowels, tongue position (and timbre), length and tenseness, vowel reduction, nasalization, and diphthongs (Sobkowiak, 2004, p. 130). What is more, he also states that if the habit of uttering British English vowels in a Polish way continues, it may lead to greater errors that are difficult to correct in time. Thus, it is mandatory for non-English learners to "accept the fact that they must abandon their native habit" (Sobkowiak, 2004, p. 210) and incorporate a new one. The method presented in this paper is a suggestion of how exactly vowels of foreign languages can be elicited by taking advantage of an emotional approach.

\section{Facial Expressions in British English Vowels Acquisition -Survey Description, Classroom Experience, and Discussion}

This section of the article contains the findings of a survey carried out with 97 second and third-year Polish students of English philology. The attempt is made to find universal emotions and facial expressions that would correlate with vowels occurring in a specific culture. The research is something that has grown from the author's own classroom experience. It is also a suggestion of how teaching sounds of a foreign language can be performed in a phonetic laboratory. It is hoped to receive further and thoughtful consideration.

Prior to conducting the survey, the notions of basic emotions and secondary emotions were introduced to the students. During a series of short lectures, the students were familiarized with the foundations of emotions. They learnt six basic emotions and what their facial expressions looked like. Accordingly, they could strive to grasp the way further emotions were derived, and what changed it triggered in the facial muscles. Unfortunately, due to the lack of time, it was impossible to check students' newly gained skills and knowledge. Thus, a presumption had to be made that the informants assimilated the material displayed in classes only to a certain. Luckily, it was compensated for by students' life experience and background knowledge related to emotions.

${ }^{5}$ [ ] - Polish vowels; no bracket-RP vowels. 
Next, the choice of emotions for the survey was made by the teacher. It was not coincidental and it was determined by two factors. First, the emotions were carefully selected based on the teacher's observation of the students in a phonetic laboratory so as to choose emotions that seemed to be most frequently used by the learners, but would not be repeated in the survey, either; it allowed respondents to understand better facial expression differences. Second, the author aimed at evoking as many positive emotions as possible to create a comfortable and aided learning class atmosphere, for which the motive is explained in another section.

For the purpose of this part of the experiment, the author recommends an exercise developed by Konstantin Stanislavsky. However hilarious or sometimes stressful the experience of the learners might be, the author and students' classroom practices indicate the accuracy and effectiveness of this method (in literature described as Stanislavsky Method (Chekhov, 2009)). The goal of the task is simply to recall a past memory or imagine a situation that is highly emotional for the learners. It helps to utter a sound accompanying the emotional state, that is to say the sound which is only seemingly coincidental for a non-English learner. For instance, in the case of /a:/, it is suggested to imagine or recall a thought of being taken aback by a situation or an entity. It helps to induce a specific emotion (in this case the emotion of surprise) and consequently stimulates lower facial muscles, along with other speech organs, to form a relevant expression corresponding to a specific British English vowel; the tongue retracts and the lips become fully round due to jaw dropping.

Lastly, the participants were asked to respond to a set of pictures (see Figure 2.1-2.12) presenting facial expressions of emotions in order to state what kind of British English vowels (see Figure 3.1-3.6) they see in them.

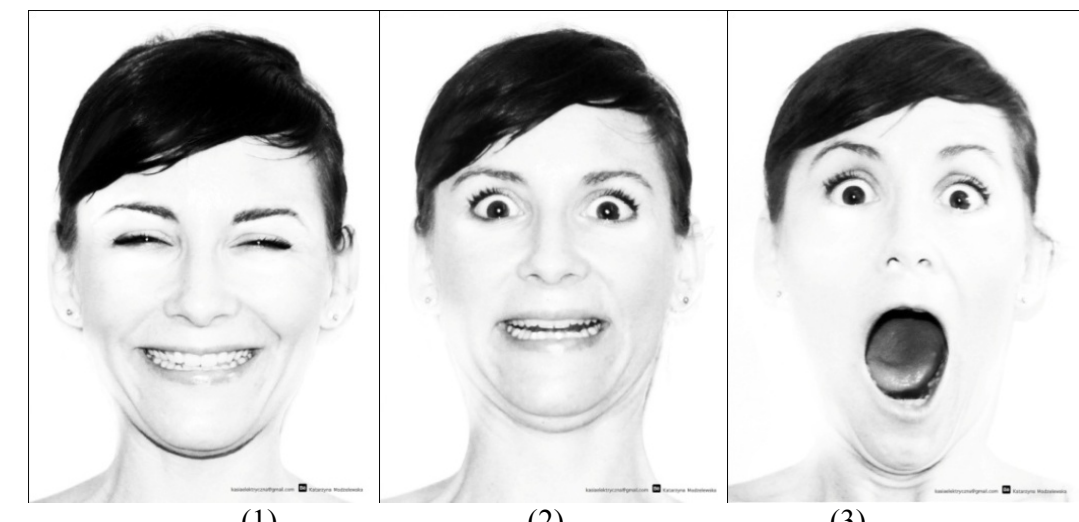

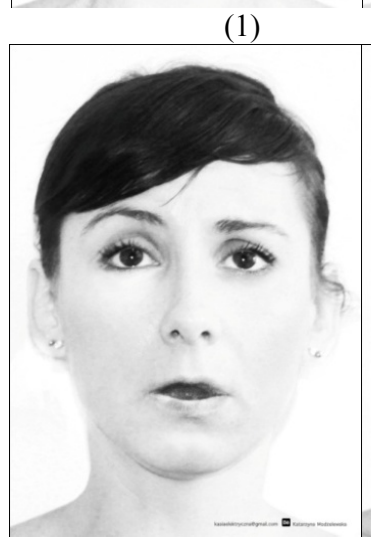

(4)

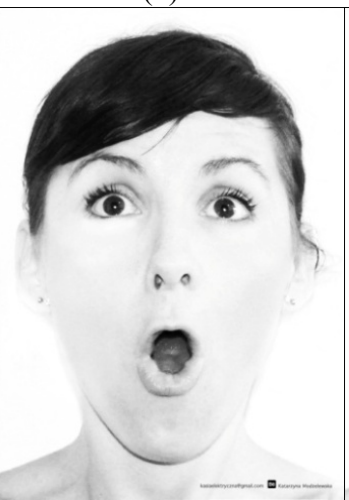

(5)

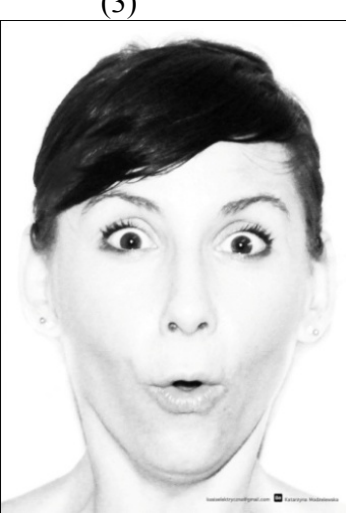

(6) 


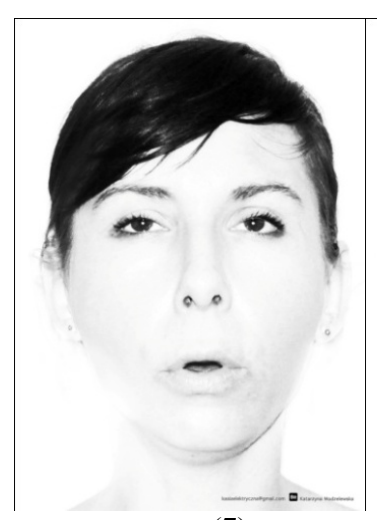

(7)

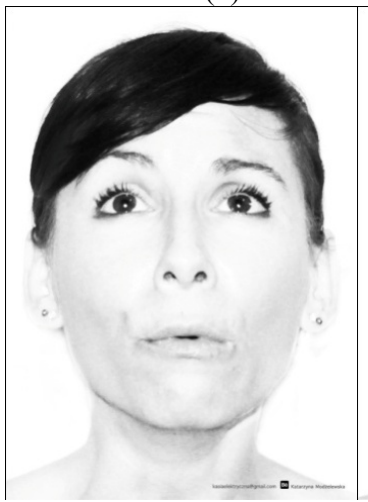

(10)

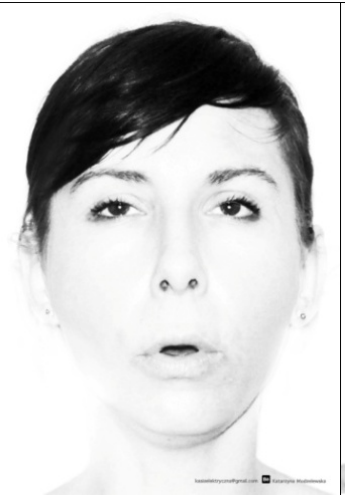

(8)

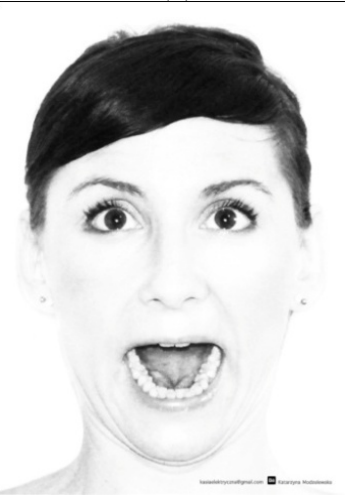

(11)

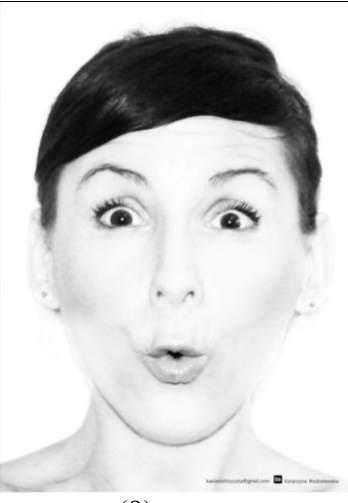

(9)

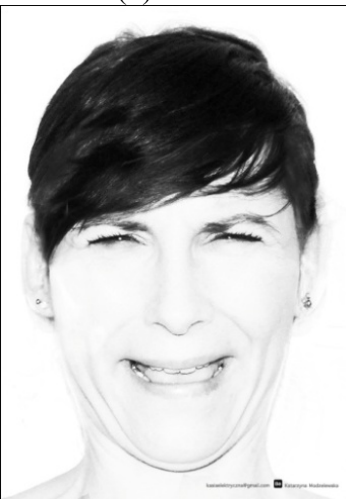

(12)

Figure 2. Facial expressions.

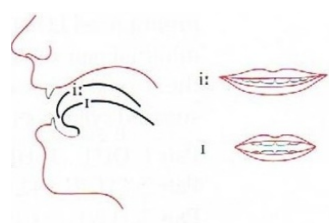

(1)

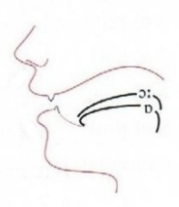

(4)

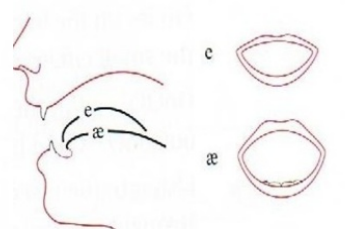

(2)

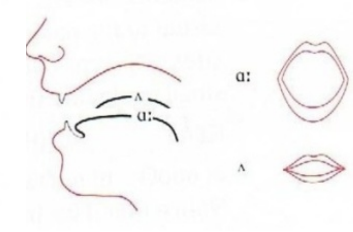

(3)

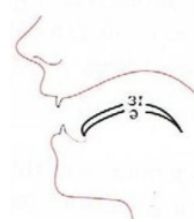

(6)

Figure 3. British English vowels-lip and tongue position.

It has to be noted that the area of the lips and the tongue position (that could not be seen in a picture for obvious reasons) were of particular interest in the survey. The upper part of the facial expression, meaning the forehead, eyebrows and eyes were of less importance. Yet, they still served the purpose of a facilitator in the process of identifying emotions and made a contribution to teaching/learning vowels.

The results of the study are presented as follows (see also Figure 4).

Figure $2.1-91 \%$ of informants ( 88 students) were able to identify that the "hidden" vowel in the emotion of happiness is /i:/. Lips are spread, upper teeth are more visible than the lower ones.

Figure $2.2-83 \%$ of informants ( 86 students) identified /I/ in the emotion of fear. Lips are slightly spread; 
upper and lower teeth are visible to the same extent.

Figure $2.3-87 \%$ of informants (84 students) recognized /a:/ in the emotion of surprise. Mouth is fully open with no clear sign of teeth.

Figure $2.4-86 \%$ of informants ( 83 students) identified $/ \Lambda$ in sadness, with a little open-mid position of the lips.

Figure $2.5-72 \%$ of informants ( 70 students) acknowledged that excitement, as a derivation from happiness, combined with surprise shows $/ \mathrm{D} /$. Mouth is open quite fully, no teeth can be observed.

Figure $2.6-72 \%$ of informants ( 70 students) agreed that the emotion being a combination of excitement, which originates from happiness and admiration (derived from happiness and surprise), holds the position of a vowel /っ:/. The lips are quite strongly rounded.

Figure 2.7 and $2.8-81 \%$ of informants (79 students) decided that the emotion of relief (as a variation of happiness) stand for $/ 3: /$ and /ə/ sounds, with neutral position of the lips in both.

Figure $2.9-72 \%$ of informants (70 students) showed that admiration being derived from happiness and surprise comprises /u:/. The lips are rather closed and moderately rounded.

Figure $2.10-81 \%$ of informants ( 79 students) stated that sadness and sympathy, as a reaction to the basic emotion of sadness, presents $/ 0 /$. The lips are slightly open and rounded.

Figure $2.11-86 \%$ of informants (83 students) claimed that shock, which is derived from fear, shows a sign of $/ æ /$.

Figure $2.12-83 \%$ of informants (81 students) attributed the emotion of disgust to /e/, with the lips spread and the upper teeth slightly raised.

\begin{tabular}{|l|l|l|l|l|}
\hline Facial expression & Emotion & Vowel & Lip position in a vowel Accuracy \\
\hline & & & & \\
\hline
\end{tabular}




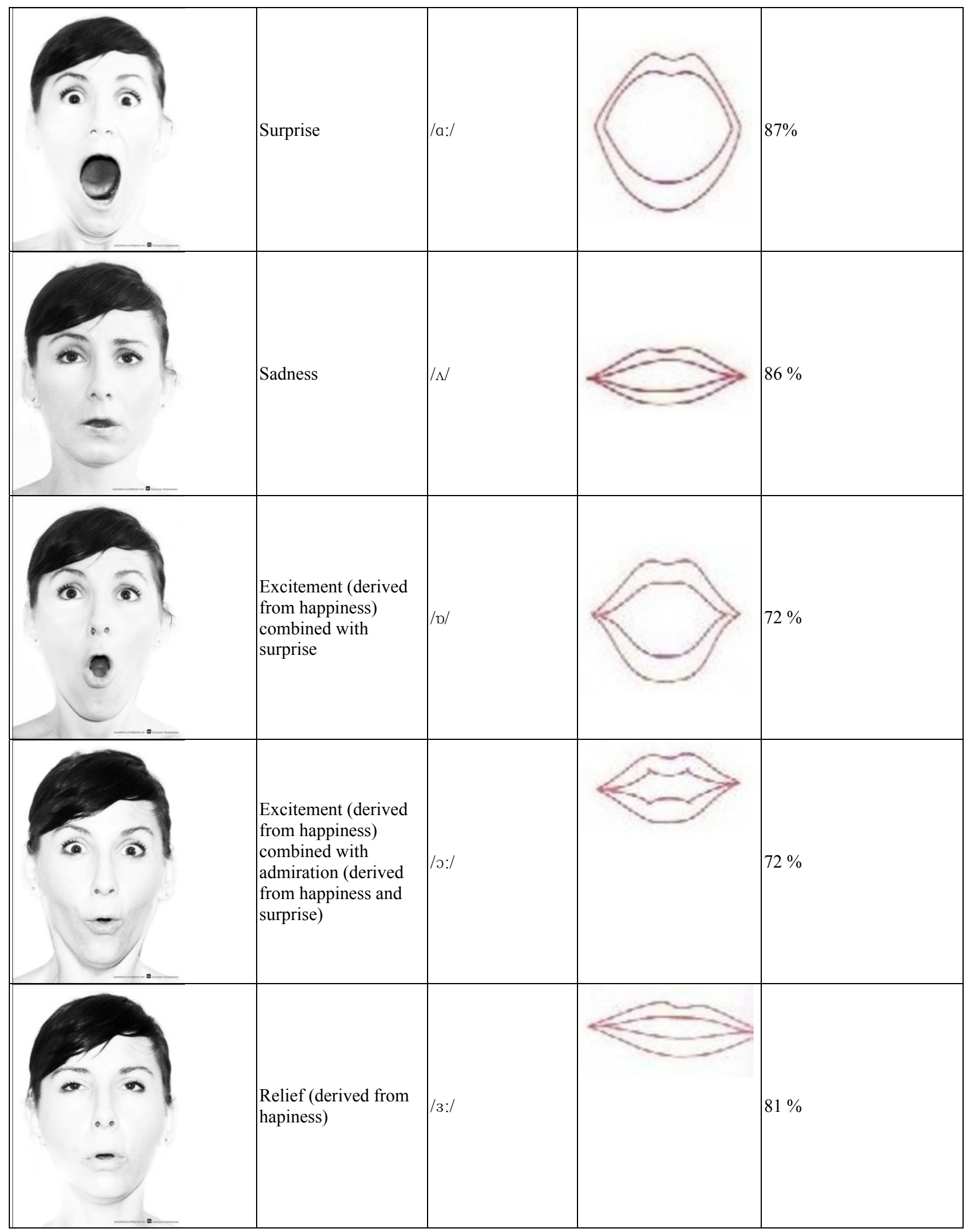




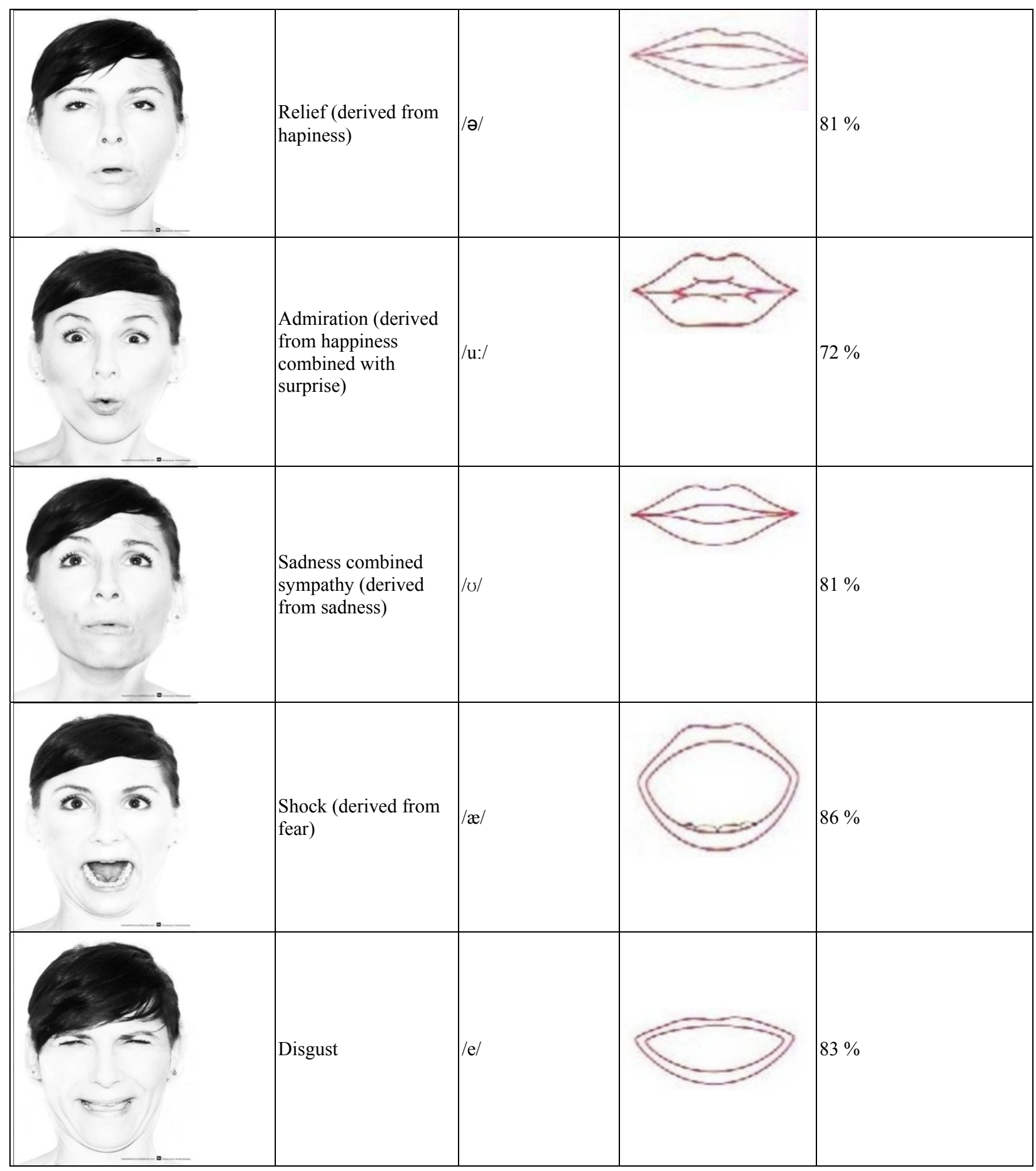

Figure 4. Facial expressions to identify British English vowels. ${ }^{6}$

\footnotetext{
${ }^{6}$ The column "Emotion" has been adapted from Ekman Paul and Friesan Wallace (1975). Unmasking the face: A guide to recognizing emotions from facial clues. Cambridge: Malor Books.; Ekman, P. (1993). Emotions revealed: Recognizing faces and feelings to improve communication and emotions. New York: Times Books.; Shaver's "Tree of Emotions" (2001, Internet resources).

The column "Lip position in a vowel" has been adapted from Baker Ann (2011). Ship or sheep?-An intermediate pronunciation course. Cambridge: Cambridge University Press.
} 
On one hand, the results may appear to be too low. As it turns out, even a group with an experience of more advanced facial expression recognition can encounter difficulty to grasp and identify emotions and their corresponding facial clues, with the ability to identify secondary emotions and combinations of emotions in particular. Despite a series of short lectures on emotional aspects, Stanislavsky Method have been put into practice, and with the training of producing vowels on demand itself, a certain number of students failed to attribute properly the sound they have uttered to the expression they have hold. Some of them admitted that they were not able to tell the difference in the set of pictures and consequently did not supply any answer. In this case, it was respondents' limited ability to understand emotions that prevented them from completing the task.

On the other hand, the results may appear to be surprisingly high; the accuracy of identifying emotions and facial expressions with British English vowels gave the total of $81 \%$. It happened so probably on account of the fact that the research was performed in a group that had already worked with the author of the article in a phonetic laboratory. The students might already have a pre-studied knowledge and expectations of facial expressions and vowels that had been based on their earlier classroom experience. Whatever the respondents provided, they might have chosen the vowels by having a prepared answer that had been formulated on what they had learned and suggested by the teacher. It did mean that they were somehow obliged to present the anticipated results. They merely and most likely decided on one, amidst a multitude of others, and the most familiar way enabling and ameliorating proper acquisition of vowels.

Another vexed question is the one of vocalization. The students were given the photos without the sounds. It was respondents' duty to associate the picture with the sound and decide how this sound can be emitted while stretching facial muscles/articulators in a specific way. Hence an illustration of a very precise score (91\%) of happiness with the sound /i:/ - a sound that is cross-culturally acknowledged and commonly produced in English when taking photos to evoke an expression of happiness of picture models by means of saying the word "cheese" /t $\int \mathrm{i}: \mathrm{z} /$ (or even quite acceptably silent "H" used to exercise pronunciation of /3:/ and /ə/). But with $/ \mathrm{D} /, / \mathrm{O}: /$, or $/ \mathrm{u}: /$, the estimate has generated only $72 \%$ since students might have had different sounds in their minds when looking at the pictures. What is more, happiness can be expressed in a number of other ways than only with the sound /i:/ and spread position of the lips (see again Figure 4.1); just like excitement or admiration unnecessarily has to possess the sounds that have been attributed by the students. Both of them, the emotions and the sounds occur to have a vast range of arrangements which are applicable depending on the purpose of their use, for this purpose of phonetic one. In this sense, when facial clues pile up and the sounds can be uttered in endless ways, the numbers that may be too low because of informants' lack of practical knowledge or too high because of prior phonetic experience seem to be justified. Thus further studies are recommended.

The very last determinant of the results of the experiment is the quality of the pictures and inability to evoke a specific emotion more vividly in order to provide an exemplary emotion with specific micro expressions, especially in the vicinity of a forehead, eyebrows, eyes, and lips. Fortunately, such kind of obstacles can be easily surmounted by developing stronger sense of an emotional attachment by the picture model while expressing emotions and/or an appropriate manipulation of the pictures.

There is a series of research that the author intends to undertake in pursuit of what has already been established. A larger number of respondents are expected to participate in an experiment and more time will be devoted to the introduction and understanding the notions of emotions (both-primary and secondary and combinations of those emotions). Such a course of action should confirm the relations between emotions and 
vowels and specify them. As far as the studies go, the sounds will be added, too. Owing to delving into the field of vocalization, new sets of expressions-vowels links should be revealed, connections that could be successfully used in phonetic classes afterwards. Additionally, assuming that the above goals can be achieved, it would be vital to consider extending the method to involve other languages (e.g., Spanish, Italian, or German) than just English. There is a difference between the productions of sounds that are culturally conditioned. But it is always possible to find suitable facial expressions of emotions which are universal for all cultures.

\section{Why the Emotional Approach?}

It has been already stipulated that the process of teaching vowels (and foreign pronunciation in general) should be physical and emotional. Such an approach has profound results. But not only does it allow non-English speakers to learn proper pronunciation faster and more accurately, but also it performs two other crucial functions.

Firstly, it enhances students' memory and cognitive abilities. Manfred Spinzter in his book The Mind Within the Net: Models of Learning, Thinking, and Acting (Spitzer, 2008) cites an experiment in which the relationship between memory and emotional involvement was studied. The experiment involved presented the story of the same length to two groups. The story was of more or less the same content. The second group heard it with a greater emotional dose, though. After a week, the informants were asked to tell how well they had memorized the story. It was revealed that the details of the story were far better remembered by those who had heard its more emotional version. The experiment proved that emotional involvement significantly improved learning abilities. As Paula Niedenthal and Marc Setterlund confirm in an academic textbook on general psychology: "Experiencing a particular emotional state should activate semantic words in memory, should strengthen the relationship between the state and the memory, and consequently facilitate the perception" (Strelau, 2004, p. 378).

Not only do emotional states aid memory, but cognitive and receptive skills as well.

"People perceive and memorize better entities of greater emotional value" (Anglart-Maciejewska, 2012).

Secondly, it increases students' self-awareness and social competences. The results of the survey showed that some students were still unable to recognize emotions - some students could not decide on specific emotions presented in the picture, while others probably unintentionally mistook one emotion for another. It is one of the reasons, which have been provided in section three of the paper, of errors constituting a significant problem. As it appears from the outlines of educational standards in Poland (dated June 2, 2014), the subject of emotions is frequently omitted or covered superficially at state schools or even in academic classes of departments of humanities at universities, including psychology faculties. Therefore, it is believed that steps must be taken to rectify the situation. The more learners are familiarized with aspects of emotions, particularly with aspects such as identifying them, the more emotionally orientated they become. Consequently, it leads to a better understanding of students themselves and more conscious social interactions that students take.

Lastly, it turns out that the role of the teacher is not teaching new sounds but merely eliciting sounds that learners already know. Students are often unaware that they indeed know the desired sound and have already used it many times, but deny it. Teacher's job is to bring out the sounds that students have used in the past unconsciously, and to put them into practice in a conscious way in a language laboratory. It is the author's

${ }^{7}$ See http://www.edukacja.edux.pl/p-6542-wplyw-emocji-i-inteligencjiemocjonalnej.php. 
preferred approach called "coaching" (Bennewicz, 2011). Coaching the responsibility of gaining skills is devolved down to the person being trained - it is up to them to do their utmost while learning. The coach's duty is only to help the person reach beyond their capabilities (Bennewicz, 2011, pp. 23-31), in this case-reach beyond linguistic ones.

\section{Comments}

The emotional approach in the acquisition of foreign vowels is apparently useful. For instance, when learners encounter problems with the arrangement of speech organs, the teacher prompts with the questions like: "What do you think fear looks like? What about surprise? Do you remember a situation when you were shocked or maybe happy? What is your reaction to something beautiful?" etc., and adds: "Hold this facial expression and make a sound, please, because that is the sound we've been looking for". Articulation varies culturally; facial expressions do not.

Two essential rules have to be observed. The first one applies to teachers. They must control the situation in the classroom at all times. Before provoking a person to express an emotion, the participant has to be informed beforehand, so that the person would not feel intimidated (Grzesiak, 2009, pp. 277-306) and everyone in the laboratory would feel safe. The second one is moderation. Although the methods from the field of psychology of emotions are effective, they should not be overused. If so, the students may get upset or grow tired. It is important to use common sense.

\section{Conclusion}

Emotions are universal in all cultures. They have their corresponding facial expressions which are universal, too.

The process of teaching pronunciation should not be perceived only as a mental process. Teaching pronunciation is a physical process and should be regarded as such.

Teaching pronunciation is an emotional process. Conscious manipulation of emotions in search of appropriate facial expressions aids acquisition of foreign language vowels.

Emotions can be triggered for better absorption of phonetic structures; they also serve the purpose of increasing cognition and memory.

Conscious emotion manipulation increases students' self-awareness and develops their social competences and perception of the world.

However the method of teaching foreign vowels with an emotional approach is effective, it should be used reasonably.

Further studies on the relationship between facial expressions and vowels acquisition of foreign languages in cross-cultural pronunciation, especially in terms of vocalization, are recommended.

\section{Acknowledgements}

Monika Surawska (consult) - is a Ph.D. student at University of Social Sciences and Humanities in Warsaw, a team member in the project "Personality in Terms of Integration, Welfare and Positive Activity", which is financed by the National Science Centre, a lecturer at the Higher State School of Computer Science and Business Administration in Łomża and at "The Bogdan Jański Academy" in Łomża. She also works as a counsellor in a job centre in Łomża. She investigates the mechanisms behind personality and sports activity. 
Email: monika.surawska@wp.pl.

Katarzyna Magdalena Modzelewska (pictures, model)—comes from a musically and manually gifted family. She started her arts career in a secondary school, where she took upon the position of an editor of a school's newspaper, and pursued her passion from then on. For many years she worked as a stained glasses designer for her hometown and local facilities. Having achieved a certain level of handicraft, she moved to Edinburgh where she continued her arts education by studying Graphics and Design at Open University in Scotland. Email: kasiaelektryczna@gmail.com.

\section{References}

Anglart-Maciejewska, A. (2012). Wpływ emocji i inteligencji emocjonalnej na postępy w nauce (Influence of emotions and emotional intelligence in learning process). http://www.edukacja.edux.pl/p-6542-wplyw-emocji-i-inteligencjiemocjonalnej.php

Baker, A. (2011). Ship or sheep? An intermediate pronunciation course. Cambridge: Cambridge University Press.

Bennewicz, M. (2011). Coaching i mentoring w praktyce. Podręcznik dla menadżerów, zawodowych coachów i pasjonatów (Coaching and mentoring in practice: Handbook for managers, professional coaches and enthusiasts). Warsaw: GJ Gruner.

Chekhov, M. A. (2009). The art of the actor. Krakow: Arche.

Curriculum for Psychology Faculties in Poland. $\quad$ (2014). $\quad$ Retrieved from:http://www.nauka.gov.pl/g2/oryginal/2013_05/1ce38c288f0711cbd7fde4439592214e.pdf

Ekman, P., \& Friesan, W. (1975). Unmasking the face: A guide to recognizing emotions from facial clues. Cambridge: Malor Books.

Ekman, P. (1993). Emotions revealed: Recognizing faces and feelings to improve communication and emotions. New York: Times Books.

Ekman, P., \& Davidson, R. (2002). Natura emocji: podstawowe zagadnienia (The nature of emotion: Fundamental questions). Gdańsk: Gdańskie Wydawnictwo Psychologiczne.

Grzesiak, M. (2009). Wyjatkowy nauczyciel. Szkolenia XXI wieku (Exceptional Teacher. Trainings for the 22nd century). Warsaw: GJ Gruner.

Harmer, J. (2011). The practice of English language teaching (3rd ed.). Harlow: Pearson Education Limited.

Kelly, G. (2000). How to teach pronunciation. Harlow: Pearson Education Limited.

Komorowska, H. (2005). Metodyka nauczania języków obcych (Methodology of teaching foreign languages). Warsaw: Fraszka edukacyjna Sp. z.o.o.

Knapp, M. L., \& Hall, J. A. (2000). Komunikacja niewerbalna $w$ interakcjach międzyludzkich (Nonverbal communication in human interaction). Wroclaw: Wydawnictwo Astrum.

Roach, P. (2002). A little encyclopaedia of phonetics. Reading: University of Reading.

Roach, P. (2012). English phonetics and phonology: A practical course (4th ed.). Cambridge: Cambridge University Press.

Scrivener, J. (2011). Learning teaching: 3rd Edition Student's Book Pack (Books for Teachers). Oxford: MacMillan.

Shaver, P., Schwartz, J., Kirson, D., \& O’Connor, C. (2001). Tree structure of emotions. Retrieved from: http://changingminds.org/explanations/emotions/basic\%20emotions.htm

Sobkowiak, W. (2008). English phonetics for poles. Poznań: Wydawnictwo poznańskie.

Sobkowiak, W. (2013). Czworokat samogłoskowy (Cardinal vowel diagram). Retrieved from: http://wa.amu.edu.pl/wa/files/ifa/pigulka/3.1.htm

Spitzer, M. (2008). Jak uczy się mózg? (The Mind within the Net: Models of learning, thinking and acting). Warsaw: PWN.

Strelau, J. (Ed.). (2009). Psychologia. Podręcznik akademicki. (Psychology. Academic Handbook on General Psychology). Sopot: Gdańskie Wydawnictwa Psychologiczne.

Underhill, A. (2007). Successful pronunciation learning. Seminar for English Language Teachers. Oxford: University of Oxford.

Underhill, A. (2007). Successful pronunciation learning. Teacher Training Workshop DVD, Macmillan.

Underhill, A. (2012). Make pronunciation physical, visible, audible! Macmillan Online Conference, Macmillan.

Wells, C. J. (Ed.). (2008). Pronunciation dictionary (3rd ed.). Harlow: Pearson Education.

Wyciński, M. (2013). Psychofizjologia i emocje w nauczaniu fonetyki języka angielskiego (Psychophysiology and emotions in teaching English phonetics). Łomża: PWSIiP. 